\title{
Functional status measurement in COPD: a review of available methods and their feasibility in primary care
}

\author{
*Janwillem WH Kocks ${ }^{\mathrm{a}, \mathrm{b}}$, Guus M Asijee ${ }^{\mathrm{c}, \mathrm{d}}$, loanna G Tsiligianni ${ }^{\mathrm{a}, \mathrm{b}, \mathrm{e}}$, \\ Huib AM Kerstjens ${ }^{\mathrm{b}, \mathrm{f}}$, Thys van der Molen ${ }^{\mathrm{a}, \mathrm{b}}$
}

a Department of General Practice, University Medical Center Groningen, University of Groningen, Groningen, The Netherlands.

${ }^{b}$ Groningen Research Institute for Asthma and COPD (GRIAC), University Medical Center Groningen, University of Groningen, Groningen, The Netherlands

'Boehringer Ingelheim, Alkmaar, The Netherlands

d Department of General Practice, Caphri Institute, University of Maastricht, The Netherlands

Agia Barbara Health Care Centre, Heraklion, Crete, Greece.

Department of Pulmonary Diseases and Tuberculosis, University Medical Center Groningen, University of Groningen, Groningen,

The Netherlands

Originally submitted 8th December 2010; revised version received 17th January 2011; accepted 18th January 2011; online 26th April 2011

\begin{abstract}
Aims: Guidelines advocate that improvement in functional status should be a major goal in COPD treatment. Many tools are available to assess aspects of functional status. This review aims to categorise systematically the available tools based on their construct (i.e. what the tool intends to measure) and to rate the tools for use in the primary care setting.

Methods: PubMed was searched with the keywords 'functional status' or 'physical capacity' or 'functional capacity' and 'COPD'. All tools were categorised and rated on their measurement properties, feasibility, and usage in primary care COPD patients. The tools were divided into four constructs - functional capacity, functional performance, functional reserve, and capacity utilisation - and used the following modes of measurement: laboratory tests; semi-laboratory tests; field tests; and patient-reported outcomes.

Results: The PubMed search resulted in 364 articles. Thirty-two tools were identified and rated.

Conclusions: In primary care, the 6-minute walking distance test is the most reliable semi-laboratory functional capacity test, but is not very practical. The pedometer is the best functional performance field test. The Medical Research Council (MRC) dyspnoea questionnaire and the functional status domain of the Clinical COPD Questionnaire (CCQ) are the best patient-reported outcome tools to assess functional performance.

(C) 2011 Primary Care Respiratory Society UK. All rights reserved. JWH Kocks, et al. Prim Care Respir J 2011; 20(3): 269-275

http://dx.doi.org/10.4104/pcrj.2011.00031
\end{abstract}

Keywords COPD, management, primary care, functional status, physical capacity, performance, measurement, tools

See linked editorial by Jones on pg 227

\section{Introduction}

The amount of physical activity possible and the functional status of COPD patients predict exacerbations, ${ }^{1,2}$ hospital admissions, ${ }^{2}$ and mortality. ${ }^{3}$ Therefore, guidelines advocate the need to designate improvement in functional status as one of the major treatment goals for patients with COPD. ${ }^{4,5}$ However, most guidelines do not define "functional status", nor do they define how to assess it.

In routine clinical practice, functional status can be measured by several different methods representing different constructs. The "construct" of a measurement or questionnaire is what the tool intends to measure. Functional status, functional capacity, exercise capacity, and exercise tolerance are terms which are often used interchangeably, but they represent different constructs. Leidy defined a theoretical framework of functional status, exercise capacity and functional capacity, and defined

\footnotetext{
* Corresponding author: Dr Janwillem WH Kocks, University Medical Center Groningen, University of Groningen, Department of General Practice A. Deusinglaan 1, 9713 AV Groningen, The Netherlands. Tel: +31-50-3632971 Fax: +31-50-3632964 E-mail: j.w.h.kocks@med.umcg.nl
} 
functional status as a 'multidimensional concept characterising one's ability to provide for the necessities of life; that is, those activities people do in the normal course of their lives to meet basic needs, fulfil usual roles, and maintain their health and wellbeing'. The framework labels and clearly defines four distinct, but related, constructs of functional status: functional capacity, functional performance, functional reserve, and capacity utilisation. Functional capacity is defined as 'one's maximum potential to perform activities' and can be tested, for example, using cycle ergometry. Functional performance is defined as the physical, psychological, social, occupational, and spiritual activities people actually do in the normal course of their lives to meet basic needs, fulfil usual roles, and maintain their health and well being. Functional reserve is the difference between capacity and performance, and capacity utilisation is the effort used to reach the functional performance. This framework is graphically represented in Figure 1.

It is important to keep this framework in mind when selecting tools for research or clinical practice. For research purposes the improvement in functional capacity may be the most important factor and be directly related to the intervention, but for clinical management an indication of the limitations that patients experience in daily life - i.e. their functional performance - is more informative.

For research purposes, measurement properties such as validity and responsiveness are of great importance in order to detect even the smallest effects of treatment. These high standards often lead to intensive, time-consuming and costly tests. For clinical practice, high measurement standards are equally important, but so too is feasibility. Measurement tools that are not easy to administer will not be used in routine practice, ${ }^{7,8}$ and so they should be feasible and easy to interpret.

Measurement tools can also be categorised according to the

Figure 1. Theoretical framework of functional status constructs by Leidy. ${ }^{6}$ Reprinted with permission from $\mathrm{N}$. Leidy, Functional status and the forward progress of merry-go-rounds: Toward a coherent analytical framework. Nurs Res 1994;43:196-202

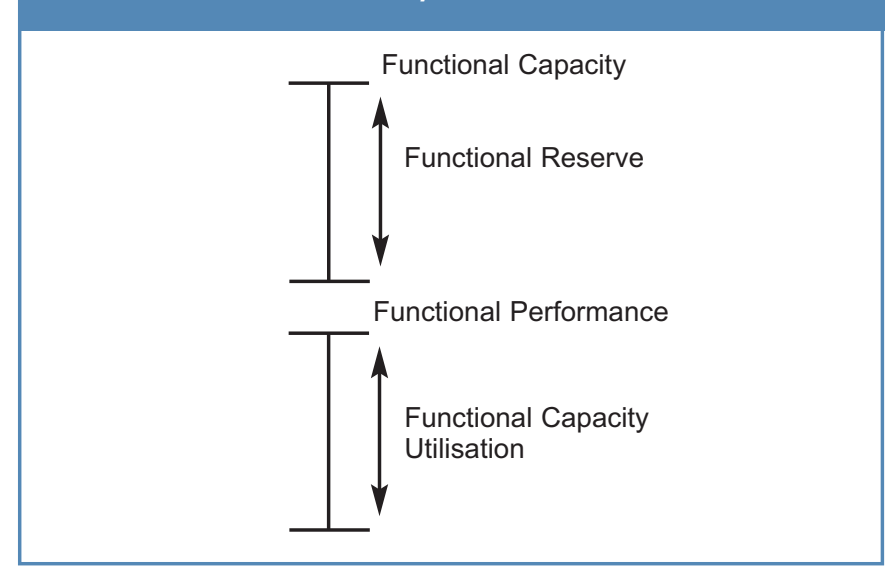

methods and resources needed to perform the measurement. In this article we have categorised measurement tools into:

1) laboratory tests - e.g. cycle ergometry ${ }^{9}$

2) semi-laboratory tests - e.g. the 6-minute walking distance test $\mathrm{t}^{10}$

3) field tests - e.g. the accelerometer ${ }^{11}$, and

4) patient-reported outcomes - e.g. the MRC dyspnoea scale ${ }^{12}$ and the St George's Respiratory Questionnaire $(S G R Q)^{13}$.

Putting measurement tools into a framework based on the construct they measure and the resources needed should help clinicians make better choices regarding the tools they use in routine practice. However, since the number of tools used to measure functional status for patients with COPD is large, and each tool has its own measurement properties, we conducted a literature search to compare the various tools available. This review summarises and rates the tools in a framework - based on the construct they measure and the resources needed - to create an overview of functional status measurements in primary care clinical practice.

\section{Methods}

\section{Literature search}

We searched PubMed using the following keywords: 'functional status' on 'physical capacity' or 'functional capacity' and 'COPD'. The timeframe for the literature search was the last 15 years, i.e. from 1st January 1995 to 1st July 2010. Studies published in languages other than English were excluded. No attempt to assess the quality of the studies was made as this was beyond the scope of this article.

The resulting titles, abstracts and texts were screened by three authors (JWHK, GMA, TvdM) for tools that were used in patients with COPD to assess exercise capacity, functional status or functional capacity. This resulted in the identification of a set of relevant tools. Following the identification of these tools, the article describing the development or implementation of the corresponding tool was reviewed for further information. To complete the PubMed search, articles that referenced the development article were searched using the "citing articles" function on ISI web of science.

\section{Data collection and scoring of tool properties}

For all tools, information was obtained about the time to complete, time for the patient to recover after performing the test, the test properties (reproducibility, reliability, validity, and responsiveness), the existence of the minimal clinically important difference (MCID), and about data in different COPD severity groups.

Based on this information, scoring of the tools was done according to the previously-used International Primary Care Respiratory Group (IPCRG) rating system. ${ }^{14}$ This system was developed to compare quickly the usefulness for clinical practice of 'COPD wellness tools'. Tools were attributed the 


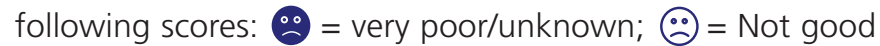
enough, if this criterion is important; $\odot=$ Good enough; (-) = Recommended $; 0$ = Highly recommended.

For all tools, scores were given in the following categories:

Validity/reliability: Articles reporting the development of the tool and further validation of instruments were used to rate the validity and the reliability. For questionnaires, a high Crohnbach's alpha is suggested (> 0.9) for use in individual patient care. ${ }^{15}$ If a tool scored highly on these items, preferably in several papers, the rating was "highly recommended".

Responsiveness: if a tool had been shown to be able to measure changes in the patient's situation - for example, during exacerbations or upon efficacious treatment - the tool was rated "recommended". If a tool appeared to be very responsive in multiple events (e.g. exacerbations, smoking cessation, pulmonary rehabilitation), the rating was "highly recommended".

Primary care population: if a tool was developed in patients with mild to moderate COPD, or the tool had successfully been used in this population, the tool was rated "recommended" or "highly recommended" based on the number and size of the studies.

Practical/Easy to administer: a tool was rated "highly recommended" when the application of the tool results in completion within 5 minutes, the scores/values are easy to calculate and interpret, no or very little additional resources are needed (e.g. additional rooms or (electronic) devices), and the patient recovery time is limited.

Tested in practice (COPD): if according to published articles tools are used in clinical practice or if guidelines recommend their use, these tools received "recommended" or "highly recommended" ratings.
MCID known: if the minimal clinically important difference is published, the rating was "highly recommended". If the tool is part of a larger questionnaire, and the total questionnaire's MCID is known, but not the part/domain's MCID, the tool was rated "recommended".

\section{Results}

The PubMed search resulted in 364 articles. Thirty-two tools were identified. The tools were divided into four categories:

1. laboratory tests

2. semi-laboratory tests

3. field tests, and

4. patient-reported outcomes.

The tools and ratings are presented in Table 1. References mentioned in the table are development articles, further validation articles, manuals or reviews describing the properties of the tools.

\section{Discussion}

This review is the first that has systematically organised tools measuring functional status in COPD within a framework by assessing the exact construct that they measure as well as the resources needed for their use. The measurement properties of each tool were graded based on the existing literature, and feasibility was graded on predefined criteria.

To assess functional status in COPD patients, this study revealed that although there is a variety of tools to assess functional status in COPD no one tool meets all the criteria for it to be highly recommended for primary care use. The 6-minute walking distance test is the most reliable, but not a very practical semi-laboratory functional capacity test. The pedometer is the best functional performance field test, and the MRC and the

\section{Table 1. Measurements and scores}

\begin{tabular}{|c|c|c|c|c|c|c|c|c|}
\hline Category & $\begin{array}{l}\text { Dimension } \\
\text { of functional } \\
\text { status }\end{array}$ & Tool & $\begin{array}{l}\text { Validity/ } \\
\text { Reliability }\end{array}$ & Responsive & $\begin{array}{l}\text { Primary } \\
\text { Care } \\
\text { Population }\end{array}$ & $\begin{array}{l}\text { Practical/ } \\
\text { Easy to } \\
\text { Administer }\end{array}$ & $\begin{array}{l}\text { Tested in } \\
\text { Practice } \\
\text { (COPD) }\end{array}$ & $\begin{array}{l}\text { MCID } \\
\text { known }\end{array}$ \\
\hline 1. Lab & Cap & Cycle ergometry ${ }^{9}$ & 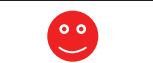 & 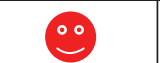 & 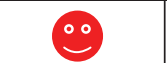 & $\stackrel{\circ}{\circ}$ & () & $\circ$ \\
\hline 1. Lab & Cap & Shuttle walk test ${ }^{9}$ & $\circ$ & $\because$ & $\ominus$ & 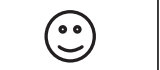 & (ச) & \\
\hline 1. Lab & Cap & Treadmill test $^{9}$ & ○ & $\odot$ & () & 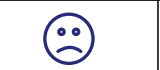 & 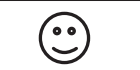 & \\
\hline 1. Lab & Per & Direct video observation & $\stackrel{\circ}{\circ}$ & $\bigodot$ & () & $\circ$ & $\circ$ & \\
\hline 2. Semi & Cap & $6 \mathrm{MWD}^{10}$ & 0 & $\circ$ & $\circ$ & (ச) & $\circ$ & $\circ$ \\
\hline 2. Semi & Cap & Master 2 step test ${ }^{16}$ & $\bigodot$ & $\circ$ & 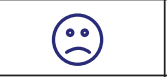 & 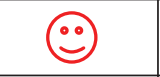 & 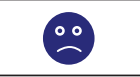 & $\circ$ \\
\hline 2. Semi & Cap & Sit to stand test" ${ }^{17}$ & 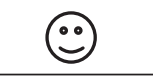 & $\bigodot$ & $\odot$ & $\circ$ & $\bigodot$ & \\
\hline 2. Semi & Cap & Stair climbing ${ }^{18}$ & $\bigodot$ & $\bigodot$ & $\bigodot$ & $\ominus$ & • & $\circ$ \\
\hline
\end{tabular}


JWH Kocks et al.

\begin{tabular}{|c|c|c|c|c|c|c|c|c|}
\hline Category & $\begin{array}{l}\text { Dimension } \\
\text { of functional } \\
\text { status }\end{array}$ & Tool & $\begin{array}{l}\text { Validity/ } \\
\text { Reliability }\end{array}$ & Responsive & $\begin{array}{l}\text { Primary } \\
\text { Care } \\
\text { Population }\end{array}$ & $\begin{array}{l}\text { Practical/ } \\
\text { Easy to } \\
\text { Administer }\end{array}$ & $\begin{array}{l}\text { Tested in } \\
\text { Practice } \\
\text { (COPD) }\end{array}$ & $\begin{array}{l}\text { MCID } \\
\text { known }\end{array}$ \\
\hline 2. Semi & Cap/per & Glittre $A D L^{19}$ & ○ & 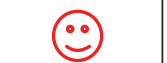 & $\bigodot$ & $\bigodot$ & $\bigodot$ & \\
\hline 3. Field & Cap/per & Energy Expenditure ${ }^{20}$ & $\circ$ & 0 & $\circ$ & & $\circ$ & \\
\hline 3. Field & Per & Pedometer $^{21}$ & ○ & $\bigodot$ & 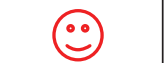 & () & 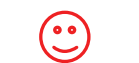 & \\
\hline 3. Field & Per & Accelerometer" & $\circ$ & & 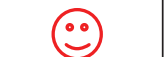 & () & (ே) & \\
\hline 3. Field & Per & Heart rate monitoring $g^{22}$ & $\circ$ & & 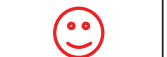 & & $\circ$ & \\
\hline 4. PRO & Per & $\begin{array}{l}\text { Activity Self Efficancy } \\
\text { Questionnaire (ASEQ) }\end{array}$ & $\circ$ & $\bigodot$ & $\circ$ & $\circ$ & $\bigodot$ & \\
\hline 4. PRO & Per & COPD Activity Rating Scale (CARS) ${ }^{24}$ & 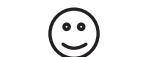 & $\bigodot$ & 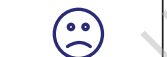 & 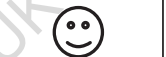 & $\bigodot$ & \\
\hline 4. PRO & Per & $\begin{array}{l}\text { Clinical COPD Questionnaire } \\
\text { functional status domain (CCQfun) }\end{array}$ & $\circ$ & & & & $\circ$ & (ச) \\
\hline 4. PRO & Per & $\begin{array}{l}\text { Capacity of Daily Living during the } \\
\text { Morning questionnaire }\left((D L M)^{27}\right.\end{array}$ & ○ & $\bigodot$ & & $\bigodot$ & $\bigodot$ & \\
\hline 4. PRO & Per & $\begin{array}{l}\text { Canadian Occupational Performance } \\
\text { Measure COPMM2829 }\end{array}$ & $\odot$ & (ت) & (ஜ) & (ஜ) & ๑) & \\
\hline 4. PRO & Per & CRQ - dyspnoea domain ${ }^{30.31}$ & $\circ$ & ) & & 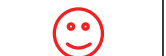 & $\circ$ & 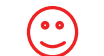 \\
\hline 4. PRO & Per & Daily record cards ${ }^{32}$ & $\because \theta$ & 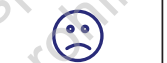 & & $\ominus$ & $\bigodot$ & \\
\hline 4. PRO & Per & $\begin{array}{l}\text { Nottingham Extended Activities of } \\
\text { Daily Living Questionnaire (EADL) } \\
\text { 33:43,35 }\end{array}$ & ๑) & 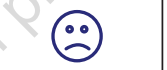 & 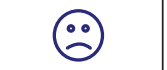 & 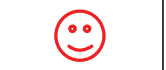 & $\bigodot$ & \\
\hline 4. PRO & Per & Functional Performance Inventory (FPI) $)^{36}$ & (อ) & $\bigodot$ & 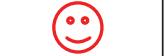 & ๑) & $\bigodot$ & \\
\hline 4. PRO & Per & Functional Status Questionnaire (FSQ ${ }^{37}$ & $\bigodot$ & $\bigodot$ & 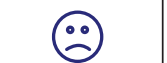 & $\bigodot$ & $\bigodot$ & \\
\hline 4. PRO & Per & $\begin{array}{l}\text { General Practice Physical Activity } \\
\text { Questionnaire GPPAQ }{ }^{38}\end{array}$ & $\ominus$ & $\bigodot$ & - & $\circ$ & $\bigodot$ & \\
\hline 4. PRO & Per & $\begin{array}{l}\text { London Chest Activity of Daily Living } \\
\text { scale (LCADL) }\end{array}$ & $\bigodot$ & $\bigodot$ & 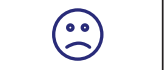 & $\circ$ & $\bigodot$ & \\
\hline 4. PRO & Per & $\begin{array}{l}\text { Modified Activity Record } \\
\text { Questionnaire (MARQ) })^{39}\end{array}$ & & 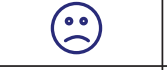 & & ๑) & $\bigodot$ & \\
\hline 4. PRO & Per & $\begin{array}{l}\text { Manchester Respiratory Activities of } \\
\text { Daily Living Questionnaire (MAADLQ) }\end{array}$ & $\circ$ & $\circ$ & 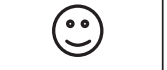 & $\circ$ & $\bigodot$ & \\
\hline 4. PRO & Per & $\begin{array}{l}\text { Medical Research Council dyspnoea } \\
\text { questionnaire }(\mathrm{MRC})^{12}\end{array}$ & $\ddot{\theta}$ & 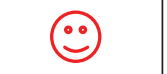 & & & $\circ$ & $\circ$ \\
\hline 4. PRO & Per & $\begin{array}{l}\text { Pulmonary Functional Status and } \\
\text { Dyspnea Questionnaire (PFSDQ) })^{4,1,22}\end{array}$ & $\bigodot$ & 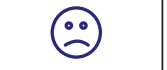 & $\ominus$ & 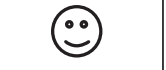 & $\bigodot$ & \\
\hline 4. PRO & Per & $\begin{array}{l}\text { Pulmonary Functional Status Scale } \\
(\text { PFSS) })^{43}\end{array}$ & 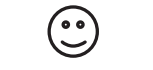 & 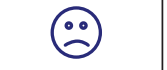 & 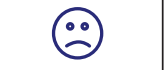 & 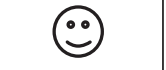 & 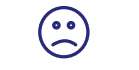 & \\
\hline 4. PRO & Per & SGRQ - activity domain ${ }^{13}$ & ○ & 0 & $\bigodot$ & $\bigodot$ & 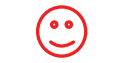 & $\bigodot$ \\
\hline 4. PRO & Per & $\begin{array}{l}\text { Short QUestionnaire to ASsess } \\
\text { Health-enhancing physical activity } \\
(\text { SQUASH) })^{44}\end{array}$ & 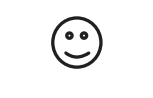 & $\bigodot$ & 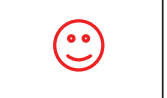 & 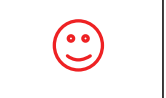 & 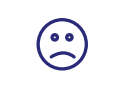 & \\
\hline
\end{tabular}

Description of label: $:=$ = very poor/unknown; $: ;=$ Not good enough, if this criterion is important; $: ;=$ Good enough; $;:=$ Recommended; $:-$ = Highly recommended $\mathrm{Lab}=$ laboratory tests; semi = semi-laboratory tests; field = field tests; PRO = patient-reported outcomes; cap = functional capacity; per = functional performance. References refer to manuals, development or validation studies. 
CCQ functional status domain are the best patient-reported outcome tools.

The number of published studies measuring functional status in COPD patients has increased rapidly in the past years. In 2000, 18 articles were found using our search strategy, whereas in 2009 there were 40. This increase in publications reflects the increasing awareness that something more than lung function is impaired in COPD patients, and that functional status is one of those impaired dimensions. There are only two conceptual frameworks currently available in which functional status is described - Leidy's model, ${ }^{6}$ and a model described by Larson..$^{45}$ Given the increased attention on functional status, it is likely that more conceptual frameworks will be developed. An example is the new conceptual framework being developed as part of the PROactive program (personal communication M. Puhan, www.proactivecopd.com).

The framework we created is based on an existing framework developed by Leidy, ${ }^{6}$ and we extended this by adding aspects on the resources needed to perform the test. Leidy et al. divided functional status into functional capacity, functional performance, functional reserve and capacity utilisation. Since functional reserve is the difference between capacity and performance, no specific tests have been developed to measure this theoretical construct. Capacity utilisation - which represents the effort that the patient needs to reach the functional performance - might be one of the most important constructs but it is not represented as a separate tool in the literature. We therefore ended up dividing the measurement tools into "functional capacity" and "functional performance" tools. However, two tools - the Glittre ADL ${ }^{19}$ and Energy Expenditure ${ }^{20}$ - were categorised as being both capacity and performance tests. The 6-minute walking distance test (6MWD) shows characteristics of both functional capacity and functional performance, although it is considered a test for functional capacity. ${ }^{10}$ The 6MWD has shown good correlation with functional performance measures such as motion sensors ${ }^{46,47}$ and is indeed more related to functional performance - measured with patient reported outcomes - than exercise capacity, as measured by cycle ergometry in patients with severe emphysema. ${ }^{48}$

In addition to the categorisation into constructs, we divided the tools into methods according to the resources needed - i.e. laboratory tests, semi-laboratory tests, field tests, and patientreported outcome tests. Using this framework we rated the most important measurement features which include validity and reliability, responsiveness, the validation in primary care COPD patients, the feasibility, the usage in primary care, and the availability of the MCID.

Despite the difficulty in categorising certain tests, the combination of Leidy's framework ${ }^{6}$ and our resources framework gives a good overview of available current functional status measurement tools and a guide for choosing tools which are feasible for use in primary care.

This study focussed on tools for patients with mild to moderate COPD, and in Table 1 the rating for this patient group is shown. Internationally, there is considerable variation between countries in terms of where patients are treated - either in primary or in secondary care. In some countries, all stages of COPD are treated mainly in primary care, whereas in others such as in The Netherlands - most patients with severe COPD are managed in secondary care. Most tools have been developed in more severe COPD patients, and therefore we explicitly focussed in our rating system on mild to moderate COPD; in milder patients the measurement properties are more difficult to obtain from the literature. Nevertheless, within the group of mild patients (as defined by lung function), patients with more impaired functional status may benefit most from interventions. ${ }^{49}$

Categorisation can help to select the most appropriate measurement in specific situations. In clinical settings, it is important that physicians realise what they measure in a patient, why they measure it, and how valid this measurement is. For example, a capacity test like cycle ergometry is very valid and can reveal true (limitations in) maximum capacity. In COPD, the limitation of capacity can be linked to the loss of pulmonary function. When the capacity limitation cannot be explained by pulmonary function loss, this might be a reason to re-examine the patient for co-morbidities. Although laboratory capacity tests might be very useful in hospital-based clinical settings, for primary care the field tests and patient-reported outcomes (PROs) are more feasible. However, field tests and PROs always test performance and not capacity. Clinical conclusions drawn from these tests might therefore differ from conclusions based on (laboratory-based) capacity tests. An additional complication of functional status PROs is that although categorised as performance tests, most PROs measure patient-perceived performance limitations and/or symptom burden during performance. Correlations between motion sensors measuring actual performance and functional status PROs are therefore moderate. ${ }^{11}$ Only the SQUASH measures the amount of physical activity; the MRADLQ measures whether or not activities are performed (with or without help). But both show poor measurement properties.

Not all tests are standardised, making it difficult to compare them between settings and between studies. For example, the stair climbing test was performed in a hospital setting with 16 flights of stairs and was stopped after exhaustion or chest pain and conducted at the patient's own pace ${ }^{18}$ or at maximal speed ${ }^{50}$ or after 35 seconds counting the maximum number of stairs. ${ }^{51}$ Although the test is cheap (and if you have stairs in your practice, can easily be performed), it lacks standardisation. However, for individual follow-up of patients in the same setting it might be useful. 
Standardised health status questionnaires with a separate functional status domain were included in this review (SGRQ, CRQ, CCQ). These domains are often separately described in studies. However, it is not advisable to create a "new" questionnaire that only uses the separate domain, because that creates new tests and alters the validity. ${ }^{52}$ The advantage of a domain within a health status scale is that with one tool, different aspects of the health impairment caused by the disease are measured.

Like many medical tests, functional status examination tests can be used to support the diagnostic trajectory but can also be used for monitoring purposes only. In clinical practice, capacity tests like cycle ergometry are often used as a diagnostic tool, ${ }^{9}$ whereas PROs are suggested as evaluation tools. Since patientreported outcomes are "precision instruments", 52 and instruments are being developed ${ }^{26,53}$ and validated ${ }^{54}$ for use in daily clinical practice, these instruments are more often used for evaluation purposes. Although information gleaned from questionnaires is often more comprehensive and more reliable than from oral history-taking, the benefits in terms of clinical practice have yet to be established.

A limitation of this study is that the grading of the tools was done based on the literature review by JWHK and GMA. Although we had pre-defined criteria to rate the measurements, it was difficult on several occasions to rate according to the 5 "smilie" grades. For example, when a measurement was used in a large study population which included a low number of GOLD I and II patients, we discussed between the authors if "primary care population" should be rated as "good enough" or "recommended". This resulted in a less objective rating (for example, "MCID known"), but the agreement between the authors improved the validity in scoring. Where JWHK and GMA disagreed on the scoring, TvdM reviewed the literature as well and discrepancies were discussed. The ratings on "Practical/ Easy to Administer" and "Tested in Practice (COPD)" are based on the literature and not on real life experience. Our method was different from that used in an overview of COPD wellness tools for the IPCRG where researchers and clinicians were asked to rate the several COPD wellness tools. The latter method might have resulted in different scoring because of unpublished experiences.

In addition, we limited our search to PubMed, which will have resulted in most, but not all available articles. ${ }^{55}$ We have used our search to identify tools, not to review individual studies. Nevertheless, we are confident that important tools that are used in scientific work were included in this review.

In conclusion, for primary care, the 6-minute walking distance test is the most reliable, but not very practical, semilaboratory functional capacity test. The pedometer is the best functional performance field test. And the MRC and the CCQ functional status domain are the best patient-reported outcome tools to measure functional performance in primary care.

\section{Acknowledgements}

We would like to thank Milo A. Puhan, MD, PhD for his comments on the manuscript. We thank Dr. Candida Delgatty, Family/General Practitioner for her kind contribution in linguistically checking and editing this manuscript.

\section{Conflicts of interest}

GMA is an employee of Boehringer Ingelheim, The Netherlands.

\section{Funding}

Unrestricted research grant from Boehringer Ingelheim.

\section{References}

1. Fan VS, Ramsey SD, Make BJ, Martinez FJ. Physiologic variables and functional status independently predict COPD hospitalizations and emergency department visits in patients with severe COPD. COPD 2007;4(1):29-39. http://dx.doi.org/10.1080/15412550601169430

2. Pitta F, Troosters T, Probst VS, Spruit MA, Decramer M, Gosselink R. Physical Activity and Hospitalization for Exacerbation of COPD*. Chest 2006;129(3):536-44. http://dx.doi.org/10.1378/chest.129.3.536.

3. Garcia-Aymerich J, Lange P, Benet M, Schnohr P, Anto JM. Regular physical activity reduces hospital admission and mortality in chronic obstructive pulmonary disease: a population based cohort study. Thorax 2006;61(9):772-8. http://dx.doi.org/10.1136/thx.2006.060145.

4. Rabe KF, Hurd S, Anzueto A, et al. Global strategy for the diagnosis, management, and prevention of chronic obstructive pulmonary disease: GOLD executive summary. Am J Respir Crit Care Med 2007;176(6):532-55.

5. Smeele I, van Weel C, van Schayck CP, et al. M26. NHG-Standaard COPD. Huisarts en Wetenschap 2007;50(8):362-79.

6. Leidy NK. Functional status and the forward progress of merry-go-rounds: toward a coherent analytical framework. Nurs Res 1994;43(4):196-202. http://dx.doi.org/ 10.1097/00006199-199407000-00002

7. Greenhalgh J. The applications of PROs in clinical practice: what are they, do they work, and why? Qual Life Res 2009;18(1):115-23. http://dx.doi.org/10.1007/ s11136-008-9430-6.

8. Lohr KN, Zebrack BJ. Using patient-reported outcomes in clinical practice: challenges and opportunities. Qual Life Res 2009;18(1):99-107 http://dx.doi.org/10.1007/s11136-008-9413-7.

9. ERS Task Force, Palange P, Ward SA, et al. Recommendations on the use of exercise testing in clinical practice. Eur Respir J 2007;29(1):185-209 http://dx.doi.org/10.1183/09031936.00046906.

10. ATS Committee on Proficiency Standards for Clinical Pulmonary Function Laboratories. ATS statement: guidelines for the six-minute walk test. Am J Respir Crit Care Med 2002;166(1):111-17.

11. Pitta F, Troosters T, Probst VS, Spruit MA, Decramer M, Gosselink R. Quantifying physical activity in daily life with questionnaires and motion sensors in COPD. Eur Respir J 2006;27(5):1040-55.

12. Bestall JC, Paul EA, Garrod R, Garnham R, Jones PW, Wedzicha JA. Usefulness of the Medical Research Council (MRC) dyspnoea scale as a measure of disability in patients with chronic obstructive pulmonary disease. Thorax 1999;54(7):581-6. http://dx.doi.org/10.1136/thx.54.7.581

13. Jones PW, Quirk FH, Baveystock CM, Littlejohns P. A self-complete measure of health status for chronic airflow limitation. The St. George's Respiratory Questionnaire. Am Rev Respir Dis 1992;145(6):1321-7.

14. Cave A, Tsiligianni I. IPCRG Users' Guide to COPD "Wellness" Tools. 2010.

15. McHorney CA, Tarlov AR. Individual-patient monitoring in clinical practice: are available health status surveys adequate? Qual Life Res 1995;4(4):293-307. http://dx.doi.org/10.1007/BF01593882

16. Master AM. The Master two-step test. Am Heart J 1968;75(6):809-37. http://dx.doi.org/10.1016/0002-8703(68)90042-2

17. Ozalevli S, Ozden A, Itil O, Akkoclu A. Comparison of the Sit-to-Stand Test with 6 min walk test in patients with chronic obstructive pulmonary disease. Respir Med 
2007;101(2):286-93. http://dx.doi.org/10.1016/j.rmed.2006.05.007

18. Brunelli A, Al Refai M, Monteverde M, Borri A, Salati M, Fianchini A. Stair climbing test predicts cardiopulmonary complications after lung resection. Chest 2002;121(4):1106-10. http://dx.doi.org/10.1378/chest.121.4.1106

19. Skumlien S, Hagelund T, Bjortuft O, Ryg MS. A field test of functional status as performance of activities of daily living in COPD patients. Respir Med 2006;100(2):316-23. http://dx.doi.org/10.1016/j.rmed.2005.04.022.

20. Goldstein S, Askanazi J, Weissman C, Thomashow B, Kinney JM. Energy expenditure in patients with chronic obstructive pulmonary disease. Chest 1987;91(2):222-4. http://dx.doi.org/10.1378/chest.91.2.222

21. Tudor-Locke CE, Myers AM. Methodological considerations for researchers and practitioners using pedometers to measure physical (ambulatory) activity. Res $Q$ Exerc Sport 2001;72(1):1-12

22. Schutz Y, Weinsier RL, Hunter GR. Assessment of free-living physical activity in humans: an overview of currently available and proposed new measures. Obes Res 2001;9(6):368-79. http://dx.doi.org/10.1038/oby.2001.48.

23. Kaplan RM, Ries AL, Prewitt LM, Eakin E. Self-efficacy expectations predict survival for patients with chronic obstructive pulmonary disease. Health Psychol 1994;13(4):366-8. http://dx.doi.org/10.1037/0278-6133.13.4.366

24. Morimoto M, Takai K, Nakajima K, Kagawa K. Development of the chronic obstructive pulmonary disease activity rating scale: reliability, validity and factorial structure. Nurs Health Sci 2003;5(1):23-30. http://dx.doi.org/10.1046/j.14422018.2003.00131.x

25. Kocks JWH, Ven vd, Uil SM, van den Berg JWK, Asijee GM, van der Molen T. Functional status measurement in chronic obstructive pulmonary disease: the value of the functional status domain of the Clinical COPD Questionnaire. Thorax 2006;61:ii3-56.

26. van der Molen T, Willemse BW, Schokker S, Ten Hacken NH, Postma DS, Juniper EF. Development, validity and responsiveness of the Clinical COPD Questionnaire. Health Qual Life Outcomes 2003;1(1):13. http://dx.doi.org/10.1186/1477-75251-13

27. Partridge MR, Miravitlles M, Stahl E, Karlsson N, Svensson K, Welte T. Development and validation of the Capacity of Daily Living during the Morning questionnaire and the Global Chest Symptoms Questionnaire in COPD. Eur Respir J 2010;36(1):96-104. http://dx.doi.org/10.1183/09031936.00123709.

28. Law M, Baptiste S, McColl M, Opzoomer A, Polatajko H, Pollock N. The Canadian occupational performance measure: an outcome measure for occupational therapy. Can J Occup Ther 1990;57(2):82-7.

29. Sewell L, Singh SJ, Williams JE, Collier R, Morgan MD. Can individualized rehabilitation improve functional independence in elderly patients with COPD? Chest 2005;128(3):1194-200. http://dx.doi.org/10.1378/chest.128.3.1194.

30. Guyatt GH, Berman LB, Townsend M, Pugsley SO, Chambers LW. A measure of quality of life for clinical trials in chronic lung disease. Thorax 1987;42(10):773-8. http://dx.doi.org/10.1136/thx.42.10.773

31. Schunemann HJ, Puhan M, Goldstein R, Jaeschke R, Guyatt GH. Measurement properties and interpretability of the Chronic respiratory disease questionnaire (CRQ). COPD 2005;2(1):81-9. http://dx.doi.org/10.1081/COPD-200050651

32. Sandha GS, Hunt RH, Veldhuyzen van Zanten SJ. A systematic overview of the use of diary cards, quality-of-life questionnaires, and psychometric tests in treatment trials of Helicobacter pylori-positive and -negative non-ulcer dyspepsia. Scand $J$ Gastroentero/ 1999;34(3):244-9. http://dx.doi.org/10.1080/00365529950173636

33. Nouri F, Lincoln N. An extended activities of daily living scale for stroke patients. Clinical Rehabilitation 1987;1(4):301-05. http://dx.doi.org/10.1177/026921558700100409.

34. Wedzicha JA, Bestall JC, Garrod R, Garnham R, Paul EA, Jones PW. Randomized controlled trial of pulmonary rehabilitation in severe chronic obstructive pulmonary disease patients, stratified with the MRC dyspnoea scale. Eur Respir J 1998; 12(2):363-9.

35. Garrod R, Bestall JC, Paul EA, Wedzicha JA, Jones PW. Development and validation of a standardized measure of activity of daily living in patients with severe COPD: the London Chest Activity of Daily Living scale (LCADL). Respir Med 2000;94(6):589-96. http://dx.doi.org/10.1053/rmed.2000.0786.
36. Leidy NK. Psychometric properties of the functional performance inventory in patients with chronic obstructive pulmonary disease. Nurs Res 1999;48(1):20-8. http://dx.doi.org/10.1097/00006199-199901000-00004

37. Jette AM, Davies AR, Cleary PD, et al. The Functional Status Questionnaire: reliability and validity when used in primary care. J Gen Intern Med 1986;1(3):143-9. http://dx.doi.org/10.1007/BF02602324

38. Department of Health. The General Practice Physical Activity Questionnaire (GPPAQ). 2006.

39. Blair SN, Haskell WL, Ho P, et al. Assessment of habitual physical activity by a sevenday recall in a community survey and controlled experiments. Am J Epidemiol 1985;122(5):794-804.

40. Yohannes AM, Roomi J, Winn S, Connolly MJ. The Manchester Respiratory Activities of Daily Living questionnaire: development, reliability, validity, and responsiveness to pulmonary rehabilitation. J Am Geriatr Soc 2000;48(11):14961500.

41. Lareau SC, Carrieri-Kohlman V, Janson-Bjerklie S, Roos PJ. Development and testing of the Pulmonary Functional Status and Dyspnea Questionnaire (PFSDQ). Heart Lung 1994;23(3):242-50.

42. Lareau SC, Meek PM, Roos PJ. Development and testing of the modified version of the Pulmonary Functional Status and Dyspnea Questionnaire (PFSDQ-M). Heart Lung 1998;27(3):159-68. http://dx.doi.org/10.1016/S0147-9563(98)90003-6.

43. Weaver TE, Narsavage GL, Guilfoyle MJ. The development and psychometric evaluation of the Pulmonary Functional Status Scale: an instrument to assess functional status in pulmonary disease. J Cardiopulm Rehabil 1998;18(2):105-11. http://dx.doi.org/10.1097/00008483-199803000-00003

44. Wendel-Vos GCW, Schuit AJ, Saris WHM, Kromhout D. Reproducibility and relative validity of the short questionnaire to assess health-enhancing physical activity. J Clin Epidemiol 2003;56(12):1163-69. http://dx.doi.org/10.1016/S0895-4356(03)00220-8.

45. Larson JL. Functional performance and physical activity in chronic obstructive pulmonary disease: theoretical perspectives. COPD 2007;4(3):237-42. http://dx.doi.org/10.1080/15412550701480372

46. Belza B, Steele BG, Hunziker J, Lakshminaryan S, Holt L, Buchner DM. Correlates of physical activity in chronic obstructive pulmonary disease. Nurs Res 2001;50(4):195-202. http://dx.doi.org/10.1097/00006199-200107000-00003

47. Berry MJ. The relationship between exercise tolerance and other outcomes in COPD. COPD 2007;4(3):205-16. http://dx.doi.org/10.1080/15412550701480679.

48. Brown CD, Benditt JO, Sciurba FC, et al. Exercise testing in severe emphysema: association with quality of life and lung function. COPD 2008;5(2):117-24. http://dx.doi.org/10.1080/15412550801941265.

49. Kruis AL, van Adrichem J, Erkelens MR, et al. Sustained effects of integrated COPD management on health status and exercise capacity in primary care patients. Int $J$ Chron Obstruct Pulmon Dis 2010;5:407-13. http://dx.doi.org/10.2147/COPD.S9654.

50. Cataneo DC, Kobayasi S, Carvalho LR, Paccanaro RC, Cataneo AJ. Accuracy of six minute walk test, stair test and spirometry using maximal oxygen uptake as gold standard. Acta Cir Bras 2010;25(2):194-200. http://dx.doi.org/10.1590/S010286502010000200013

51. Ljungquist $T$, Jensen IB, Nygren A, Harms-Ringdahl K. Physical performance tests for people with long-term spinal pain: aspects of construct validity. J Rehabil Med 2003;35(2):69-75. http://dx.doi.org/10.1080/16501970306117

52. Juniper EF. Validated questionnaires should not be modified. Eur Respir J 2009;34(5):1015-17. http://dx.doi.org/10.1183/09031936.00110209.

53. Jones PW, Harding G, Berry P, Wiklund I, Chen WH, Kline LN. Development and first validation of the COPD Assessment Test. Eur Respir J 2009;34(3):648-54. http://dx.doi.org/10.1183/09031936.00102509

54. Kocks JW, Kerstjens HA, Snijders SL, et al. Health status in routine clinical practice: validity of the Clinical COPD Questionnaire at the individual patient level. Health Qual Life Outcomes 2010;8(1):135. http://dx.doi.org/10.1186/1477-7525-8-135.

55. Michaleff ZA, Costa LO, Moseley AM, et al. CENTRAL, PEDro, PubMed, and EMBASE Are the Most Comprehensive Databases Indexing Randomized Controlled Trials of Physical Therapy Interventions. Phys Ther 2011;91(2):190-7. http://dx.doi.org/10.2522/ptj.20100116. 